\title{
The post-coital pills as over the counter drugs
}

Sir,

Post-coital pill or emergency contraceptives are birth control measures that, if taken after sexual intercourse, may prevent pregnancy. ${ }^{1}$ High dose of postcoital contraceptives like diethylstilbestrol \& other estrogens were being used for some time without any approval by FDA. ${ }^{2}$ Task force on postovulatory methods of fertility regulations 1998, conducted clinical trials leading to approval of two preparations for postcoital contraception by FDA namely levonorgestrel $0.75 \mathrm{mg} \&$ combination of 0.25 levonorgestrel \& $0.05 \mathrm{mg}$ of ethinyl estradiol. ${ }^{3}$ Levonorgestrel is more popular in India because it is more effective \& has fewer side effects. The first dose of levonorgestrel $0.75 \mathrm{mg}$ should be taken within 72 hours of unprotected intercourse followed by a second dose after 12 hours. This treatment reduces the risk of pregnancy by approximately $75 \% .^{4}$ Oral levonorgestrel acts as an emergency contraceptive principally by preventing ovulation or fertilization by altering tubal transport of sperm and/or ova. In addition, it may inhibit implantation by altering the endometrium. It is not effective once the process of implantation has begun.

The use of post-coital pills as a contraceptive method is rising due to changing socio-cultural practices and increased awareness among target population. In India, these drugs are available as over the counter drugs (OTCs) which is a good initiative to check the population explosion in India. ${ }^{5}$ The brands like I-pill, Pill-72, Unwanted 72 etc which contain levonorgestrel $0.75 \mathrm{mg}$ $1.5 \mathrm{mg}$ are popular in India. Mifepristone $600 \mathrm{mg}$ single dose is popular as postcoital pill in China and European countries with high success rate and fewer adverse effects. Whereas in India Mifepristone - misoprostol combination is more popular as an abortifacient. It is noticed that like other OTCs these drugs are also being used irrationally and nonjudiciously. The youngsters aware about the existence and easy availability of postcoital pills may indulge in unsafe sex, increasing the incidence of STDs and menstruation related problems. ${ }^{6}$ The post coital pill is also being used as abortifacient in early pregnancy by dais, midwives and practitioners of alternative therapies etc. Such unsafe use causes incomplete abortions with excessive bleeding. The FDA's office of drug safety consultation found 3 cases of spontaneous abortion, 1 missed abortion, 1 inevitable abortion, and 3 reported European cases of congenital anomalies in pregnancies in women who had taken levonorgestrel. Given that spontaneous abortions have been reported to occur in $10-15 \%$ of clinically recognized pregnancies. ${ }^{7}$ The excessive publicity of these drugs by media without providing necessary information regarding safe use has added to the problems. The target population using this method of contraception is largely unaware of adverse drug effects and the frequency with which these could be safely used. Many times they end up using such drugs about three to four times in a month leading to higher incidence of adverse effects like gastritis, dysmenorrhoea, menorrhagia, delayed periods and high failure rate etc.

Emergency contraception is more effective in preventing pregnancy when taken as early as possible after unprotected sexual intercourse. Hence over the counter status should enhance benefit by providing more timely access to the product than through prescription. ${ }^{8}$ Although these drugs seem to be the need of the hour for controlling the population explosion, but it must be emphasized that they are used exclusively for accidental exposure or unexpected circumstances which may lead to conception and should never be used as a routine contraceptive. Though the Media is justified in supporting such a national cause of population explosion, but it should also stress upon other methods of contraception for routine use. The advertisements must provide full information necessary for educating the public about safe and effective use of these drugs. The registered practitioners especially of alternative systems medicine and workers must be kept properly informed about the approved indications and adverse effects of postcoital pills to avoid complications and increased disease burden. The NGOs and voluntary associations especially associated with various women issues should come forward and play a pivotal role in educating women about safe sex and contraception.

Sukhbir Singh, Rakesh Kumar*, Jagminder Kaur Bajaj Department of Pharmacology, Punjab Institute of Medical Sciences, Jalandhar, India

*Correspondence to: Dr. Rakesh Kumar, E-mail: bagharakesh@hotmail.com

\section{REFERENCES}

1. Hadley ME. Endocrinology, 5th edition, Prentice Hall, Upper Saddle River, New Jersey, 2000. p.467.

2. Loose-Mitchell DS, Stancel GM. Estrogens and progestins. In: Hardman JG, Limbird LE, eds. 
Goodman \& Gillman's The Pharmacological Basis of Therapeutics. 10th ed. New York, NY: McGrawHill; 2002:1624.

3. Task Force on Postovulatory Methods of Fertility Regulation. Randomized controlled trial of levonorgestrel versus the Yuzpe regimen of combination oral contraceptives for emergency contraception. Lancet. 1998;352:428-33.

4. Sarkar NN. Barriers to emergency contraception (EC): does promoting EC increase risk for contacting sexually transmitted infections, HIV/AIDS? Int J Clin Pract 2008;62:1769-75.
5. "India's population 'to be biggest' in the planet". BBC News. 2004-08-18. Retrieved 2011-09-24.

6. Staras SA, Cook RL, Clark DB. Sexual partner characteristics and sexually transmitted diseases among adolescents and young adults. Sex Transm Dis 2009;36:232-8.

7. ACOG Practice Bulletin, Clinical Management Guidelines for Obstetrician-Gynecologists; 2001, No. 24:1.

8. WHO multicenter Study 92808 submitted in the Plan B application in 1999.

doi:10.5455/2319-2003.ijbcp20130322

Cite this article as: Singh S, Kumar R, Bajaj JK. The post-coital pills as over the counter drugs. Int J Basic Clin Pharmacol 2013;2:227-8. 